\title{
A Family Medicine Residency Program's Response to an Impending COVID-19 Surge
}

Jessica Devitt, MD, Naomi Malam, MD, and Linda Montgomery, MD, FAAFP

The University of Colorado family medicine residency watched along with the rest of the nation as the first cases of COVID-19 were being reported in the United States in March 2020. Concern grew as epidemiological models began to predict alarming hospital bed shortages for the state. Massive scheduling adjustments were needed as faculty and residents found themselves in groups at high risk for severe CovID-19 and residents found themselves dismissed from nonessential learning experiences in an effort to conserve personal protective equipment and limit exposures. A dedicated surge team was formed to tackle these issues while continuing to support our goals of maximizing patient safety, resident education, and physician wellness. The surge team created a plan that was implemented in 2 main phases. Phase 1 assumed business as usual with increased layers of backup for both residents and faculty. Phase 2 redistributed unassigned residents and inpatient faculty to increase capacity for adult medicine and COVID-19 patients on our essential services. Lessons learned from these surge efforts may help inform similar decisions being made by other residency programs presently and in the future. (J Am Board Fam Med 2021;34:S217-S221.)

Keywords: Continuing Medical Education, CoVID-19, Faculty, Family Medicine, Pandemics, Patient Safety, Residency

Coronavirus disease 2019 (COVID-19) has become a pandemic that is challenging health care systems around the world. In Colorado, the first COVID19 case was reported in March 2020, ${ }^{1}$ and epidemiologic models predicted alarming hospital bed shortages for our state. ${ }^{2}$ As Colorado's Governor called for the reinstatement of inactive health care workers, preparations for a possible surge were already under way at the University of Colorado Hospital (UCH). ${ }^{3}$ In mid-March, our Family Medicine Inpatient Service (FMIS) began admitting patients suspected of having COVID-19, and it was clear that we needed to coordinate efforts with the hospital and other residency programs to mobilize providers and teams to prepare for an impending surge of hospitalized patients with COVID-19.

This article was externally peer reviewed.

Submitted 4 May 2020; revised 15 June 2020; accepted 17 June 2020.

From the Department of Family Medicine, University of Colorado School of Medicine, Aurora, CO (JD, LM); Family Medicine Residency Program, University of Colorado School of Medicine, Aurora, CO (NM).

Funding: None.

Conflicts of interests: None.

Corresponding author: Jessica Devitt, MD, University of Colorado School of Medicine, Aurora, CO 80045 (E-mail: jessica.devitt@cuanschutz.edu).
The University of Colorado Family Medicine Residency is a 13-13-13 resident program and is part of a larger graduate medical education (GME) system made up of several programs serving 1100 residents and fellows. Like many family medicine residency programs, our physicians work in both inpatient (17 inpatient trained faculty) and outpatient settings. We have 2 essential inpatient services at 2 hospitals, UCH and Denver Health Hospital. In this article, we will focus on changes made in the $\mathrm{UCH}$ system to address the demands of the developing pandemic and fulfill our teaching mission. At UCH, our FMIS runs year-round, 24 hours a day, and is composed of 2 teams; FM A, which is adult medicine only, and FM B, which is a maternity care service with adult medicine overflow. These teams cover an average total of 12 to 16 patients and are generally composed of 2 day faculty attendings, 3 day residents (2 upper-level residents and 1 intern), 1 resident on a swing shift, and 1 resident and 1 faculty attending on night coverage.

As pandemic concerns mounted, we were faced with multiple simultaneous dilemmas. It became apparent that some of our own resident and attending physicians belonged to the at-risk population for complications from COVID-19 (eg, on immunosuppre- 
ssive therapy, pregnant, etc.). We reassigned approximately $6 \%$ of residents and $18 \%$ of faculty from direct patient care to virtual care due to these concerns. Meanwhile, because of growing efforts at rotation sites to minimize provider exposure, preserve personal protective equipment (PPE), and allow for social distancing, many of our residents found themselves unassigned. At this time, we also saw a potential need for increased staffing at our hospitals as projections of bed and inferred provider shortages were being released. We assembled a "surge team" composed of our inpatient director, program director, interested inpatient faculty, and chief residents to tackle these issues while maximizing patient safety, resident education, and physician wellness. We approached our COVID-19 response in 2 phases. These phases will be described in detail, and a complete timeline for the events, responses, and interventions described herein is outlined in Table 1.

\section{Phase 1: Preserve Our Providers, Create Backup Systems, and Communicate across Specialties}

\section{Faculty}

Faculty without risk volunteered to take shifts from those who would benefit from working from home. Using our 14 remaining inpatient faculty, a schedule was created whereby all but 1 provider were able to have $>2$ weeks (a built-in quarantine period to allow for exposure/illness) away from inpatient care and there were at least 2 backup faculty on backup call for each day through the end of May. To minimize transitions of care, we scheduled providers for a minimum of 5 continuous days on service. Three exceptions were made (affecting a total of 9 days of our initial 2-month surge schedule) in which 3-day stints were allowed due to availability and to avoid overburdening certain providers. In addition, in preparation for the next phase, our department began surveying outpatient providers regarding their skillset (most recent inpatient, intensive care unit [ICU], and obstetrics [OB] experiences) and availability. An emergency volunteer pool of approximately 30 providers was created and tiered based on recency of experience.

\section{Residents}

The prepandemic backup system was expanded from 1 to 3 residents per day due to anticipated need for emergency coverage for illness/exposure or increased patient volumes. In addition, for continuity's sake, backup residents were assigned to 5to 7-day blocks rather than our previous schedule, which scattered backup call throughout the month.

\section{Family Medicine Inpatient Service}

We ensured any person under investigation (PUI) for COVID-19 was assigned to FM A to minimize exposure to moms/babies on our FM B service and placed elderly/immunocompromised adult patients preferentially on our FM B service as well. We contacted our obstetrician and pediatrician colleagues, who we have had the fortune to work alongside on labor and delivery for well over a decade, and they readily agreed to assume the care of our laborers, postpartum, and newborn patients in the event of overwhelming adult medicine patients due to COVID-19.

\section{Interdisciplinary Communication and Coordination}

In mid-March, our associate dean of education began to convene a 2 times a week meeting of the program directors of the 7 largest programs including family medicine to communicate about clinical and educational needs across programs and hospitals. Our family medicine program director (PD) became 1 of 2 PDs appointed to implement a resident reassignment system (RRS). The availability, ICU experience, and hospital access/badging status of each of 1100 residents and fellows were obtained by requesting that PDs from each program complete a spreadsheet with this information.

\section{Phase 2: Increase Capacity and Create Opportunities for Displaced Learners Faculty}

We identified a backup inpatient faculty member, using our existing backup call schedule, who could staff a new third team (FM C) in the event of a surge of COVID-19 cases in the hospital. We also created a rotating weekly schedule for the first tier of outpatient provider volunteers who could be called to cover the outpatient duties of any inpatient trained faculty member called into the hospital. A second tier of outpatient providers was identified to cover the outpatient duties of the first tier of outpatient providers should they themselves be called into hospital duties. 
Table 1. COVID-19 Event and Response Timeline

\begin{tabular}{|c|c|c|}
\hline Date & Event & Description \\
\hline March 5, 2020 & First case of COVID-19 in Colorado & \\
\hline March 12, 2020 & $\begin{array}{l}\text { Need for new backup call system identified for } \\
\text { both residents and faculty }\end{array}$ & $\begin{array}{l}\text { We needed backup providers for: } \\
\text { - Faculty and residents who needed to minimize } \\
\text { risk of COVID-19 exposure } \\
\text { - Faculty and residents who may contract the } \\
\text { illness either from the community or work } \\
\text { exposure }\end{array}$ \\
\hline March 13, 2020 & $\begin{array}{l}\text { First UCH inpatient diagnosed with COVID-19 } \\
\text { - Developed a contingency plan for our } \\
\text { maternity care service } \\
\text { - Developed a contingency plan to take more } \\
\text { adult inpatients }\end{array}$ & $\begin{array}{l}\text { - Ensured PUIs would not be on our maternity } \\
\text { care service } \\
\text { - Contacted both the obstetrics-gynecology and } \\
\text { newborn nursery directors regarding the care } \\
\text { of our moms/babies in the event of a surge of } \\
\text { adult patients } \\
\text { - Contacted the clinical director of hospital } \\
\text { medicine regarding our ability to admit more } \\
\text { adult inpatients if needed }\end{array}$ \\
\hline & Enhanced resident backup call schedule finalized & \\
\hline March 17, 2020 & Faculty backup call schedule finalized & $\begin{array}{l}12 \text { of our inpatient providers that had no } \\
\text { contraindication to COVID- } 19 \text { patient care/ } \\
\text { exposure divided up shifts and days so that all } \\
\text { but } 1 \text { provider had }>2 \text { weeks off between stints } \\
\text { and there were } 2 \text { backup providers on any given } \\
\text { day in the event of a provider getting ill }\end{array}$ \\
\hline March 19 to 22,2020 & $\begin{array}{l}\text { Department of family medicine sends surveys to } \\
\text { all providers regarding clinical experience and } \\
\text { skills }\end{array}$ & $\begin{array}{l}\text { A survey regarding clinical skills (most recent } \\
\text { inpatient, ICU, obstetric experience) and } \\
\text { availability to work in the hospital in the event } \\
\text { of a surge to inform planning for emergency } \\
\text { reassignment of providers }\end{array}$ \\
\hline March 26, 2020 & $\begin{array}{l}\text { Formal surge planning team created within the } \\
\text { family medicine residency program }\end{array}$ & $\begin{array}{l}\text { A team of faculty and residents create a schedule } \\
\text { to increase the capacity of our inpatient service } \\
\text { using residents who are likely to be displaced } \\
\text { from other rotations }\end{array}$ \\
\hline March 30, 2020 & Phase 2 resident reassignment schedule finalized & $\begin{array}{l}\text { A schedule reassigning displaced residents into } \\
\text { the UCH FM hospital schedule to increase } \\
\text { capacity and create learning experiences was } \\
\text { generated }\end{array}$ \\
\hline April 6, 2020 & $\begin{array}{l}\text { - Resident reassignment schedule implemented } \\
\text { - OB and pediatrics assume care of FM } \\
\text { maternity care service } \\
\text { - FM capacity increased from } 12 \text { to } 24 \text { patients }\end{array}$ & \\
\hline April 10, 2020 & FM A becomes a dedicated COVID-19 team & \\
\hline
\end{tabular}

UCH, University of Colorado Hospital; PUI, person under investigation; OB, obstetrics; FM, family medicine.

\section{Residents}

We redeployed all displaced residents to 1 of our 2 essential services or to the essential services of other departments in need (see below). The residents assigned to our essential services were divided into a total of 4 teams, 2 to cover each hospital. Each team was allocated 3 day residents, 1 swing resident, 2 night residents, and 2 backup residents. The backup residents not only served as a built-in backup call pool for each team but also provided support from home to the teams including leading virtual teaching sessions, calling consults, and preparing discharge summaries. Although we considered a 7-days-on/14-days-off model, we did not have the staffing to support this, and therefore adopted a 7-days-on/7-days-off model. This schedule still allowed for consistent time off and at least 1 week of recovery in the event of illness, relying on our backup call system for further needs.

We faced the dilemma of how to continue education for our residents in this new landscape. COVID-19 presented some learning opportunities in and of itself; residents both attended and helped to organize virtual lectures on COVID-19 and underwent focused PPE training, some received supervised hands-on COVID-19 care experience, others volunteered to perform contact tracing, and, finally, all of the residents had to learn how to 
practice family medicine virtually. In addition to virtual clinic sessions and didactics, residents were challenged to engage in more intense self-directed learning during nonhospital weeks. The residency leadership prepared a weekly bulletin with other virtual learning sessions, continuing medical education, maintenance of certification, and research opportunities. Residents were required to $\log$ their activities during these off-service weeks.

\section{Family Medicine Inpatient Service}

As COVID-19 admissions began to climb, our OB and pediatrics teams assumed the tending of our maternity care service in accordance with the aforementioned contingency plan. With the added resident power, we doubled the capacity of our inpatient service (12 to 24 patients) with an emergency schedule in place that would allow for even further capacity increases if needed. The FM A team transitioned into a COVID-19-only team and was staffed by 1 resident and 1 faculty attending to minimize provider exposure and help with the surge of COVID-19 patients requiring hospitalization.

\section{Interdisciplinary Communication and Coordination}

As both service and resident needs were rapidly evolving, GME leaders increased their program director meetings to 3 times per week. The RRS used the aforementioned resident database to assign qualified and available residents to services in need. Through this system, 4 of our family medicine residents $(\approx 10 \%)$ were reassigned to the COVID-19 ICU and pulmonary step-down teams.

\section{Lessons Learned}

Streamlined and centralized communication is paramount during rapid change. Due to sweeping schedule and team structure changes, communication regarding questions and troubleshooting was happening at all hours of the day via phone, e-mail, and impromptu virtual meetings. Although this communication was necessary, it was inefficient. To streamline this, our surge team scheduled a recurring weekly virtual meeting to address questions/concerns, create fixes to problems identified by those on service, and allow for the current inpatient team leaders to provide essential practice/system updates to the oncoming team leaders. In addition, weekly update e-mails and a standing virtual session during didactics were implemented to reach all residency providers. Although initially the faculty member on service at the start of the pandemic was communicating needs and updates to our OB, pediatric, and hospitalists colleagues by default, we quickly appointed (and maintained in the case of our inpatient director) individual faculty liaisons to communicate with each specialty service both as needed and at recurring meetings. This allowed us to adjust our service changes with the fluctuating needs of the hospital.

Prepare to be initially overstaffed. As no projection has proved perfect, we rolled out our surge resident schedule several days before patient volumes supporting it. To address excess staffing, the residents initially began alternating shifts in an attempt to make time off equitable. However, this resulted in unnecessary disruptions to continuity and unnecessary provider exposure. We quickly learned that excess residents should be assigned to a backup role for blocks of shifts if volumes were low, despite the risk of unequal hospital shifts.

Complete separation of teams caring for patients with and without COVID-19, although ideal, was ultimately not sustainable for our service. Due to the rise and fall of cases of patients with COVID19, we had to have a hybrid service (FM A taking both COVID-19 and non-COVID-19 patients) both at the onset of our COVID-19 surge and as those cases began to fall while non-COVID-19 admissions began to rise again. We have depended on appropriate use of PPE, hand hygiene, and prioritizing seeing any immunocompromised patients before seeing any COVID-19 patients, when possible, to minimize the risk of cross contamination. To date, we are not aware of any case of hospitalacquired COVID-19 on our service.

It has become clear that for the medical field at large, and for medical education specifically, COVID-19 is not a hurdle to cross but rather a new steady state to which we must adapt. We have presented to you our specific experiences in adjusting to this new reality. We hope the lessons we are learning from this endeavor can help guide other residency programs as they are adapting to the COVID-19 landscape.

The contributors wish to thank the UCH surge team (Kathryn Boyd-Trull, MD, Corey Lyon, DO, FAAFP, Melissa Neuman, MD, Jennifer Caragol, MD, Cristina Rabaza, MD) and Nicolas Busquet, $\mathrm{PhD}$ (editing).

To see this article online, please go to: http://jabfm.org/content/ 34/Supplement/S217.full. 


\section{References}

1. Colorado Governor Jared Polis. Updated information on COVID-19. March 5, 2020. Available from: https://www.colorado.gov/governor/news/ updated-information-covid-19. Accessed May 3, 2020.

2. Institute for Health Metrics and Evaluation. COVID19 projections. 2020. Available from: https://covid19. healthdata.org/united-states-of-america/colorado. Accessed May 1, 2020.

3. Daley J. Like emergency medicine special forces, Colorado doctors and nurses get ready to combat coronavirus. CPR News. March 15, 2020. Available from: https://www.cpr.org/2020/03/15/like-emergencymedicine-special-forces-colorado-doctors-and-nursesget-ready-to-combat-coronavirus/. Accessed May 1, 2020. 